\title{
Tribological, electrochemical and tribo-electrochemical characterization of bare and nitrided Ti6Al4V in simulated body fluid solution
}

\author{
T.M. Manhabosco ${ }^{\mathrm{a}, *}$, S.M. Tamborim ${ }^{\mathrm{b}}$, C.B. dos Santos ${ }^{\text {c }}$, I.L. Müller ${ }^{\mathrm{b}, *}$ \\ ${ }^{a}$ Physics Departament, Federal University of Ouro Preto, Campus Universitário Morro do Cruzeiro/ICEBS/DEFIS/35400-000, Ouro Preto, Minas Gerais, Brazil \\ ${ }^{\mathrm{b}}$ Metallurgy Department, Laboratory of Corrosion Research, Federal University of Rio Grande do Sul, Av. Bento Gonçalves 9500/75/232, 91501-970 Porto Alegre, \\ Rio Grande do Sul, Brazil \\ ${ }^{\mathrm{c}}$ Fraunhofer-Institut/IPA Institut für Produktionstechnik und Automatisierung, Nobelstrasse 12, Sttutgart 70569, Germany
}

\section{A R T I C L E I N F}

\section{Article history:}

Received 29 September 2010

Accepted 29 January 2011

Available online 4 February 2011

\section{Keywords:}

A. Alloy

B. EIS

C. Interfaces

\begin{abstract}
A B S T R A C T
Tribological, electrochemical and tribo-electrochemical behaviour of bare and nitrided Ti6Al4V alloy was studied. Scanning Electron Microscopy (SEM), X-ray diffraction and microhardness profile were used to characterize the nitrided Ti6Al4V. The anticorrosive properties of nitrided Ti6Al4V in phosphate buffer saline solution (PBS), simulating the body environment, were evaluated by Electrochemical Impedance Spectroscopy (EIS). Nitriding increased the alloy resistance to corrosion and to dry wear. Resistance to tribocorrosion in PBS at the open circuit potential (OCP) for the nitrided alloy was also significantly increased compared to the bare alloy; nevertheless at an anodic potential this influence became less important.
\end{abstract}

(c) 2011 Elsevier Ltd. All rights reserved.

\section{Introduction}

Biomaterials are an important research area that has expanded rapidly over the last decades. These materials are used to reestablish the function of damaged parts in the human body. Metallic biomaterials like stainless steel, Co-Cr-Mo alloys, titanium and its alloys are used in several medical devices and implants such as heart valves, stents, dental roots, hip joints, etc.

Among the metallic biomaterials exposed to mechanical solicitations, titanium and its alloys present good biocompatibility, high aspect ratio, low Young modulus (E) and excellent corrosion resistance compared to other metallic biomaterials. However, titanium and its alloys have relatively poor wear resistance [1]. Moreover, authors have criticized some alloys due to the presence of aluminium and vanadium $[2,3]$.

Surface treatments are widely employed to improve wear and corrosion resistance as well as hardness of the surface of titanium alloys [4-6]. Plasma nitriding enhances titanium properties by forming a hard compound layer composed by $\mathrm{TiN}^{2}$ and $\mathrm{Ti}_{2} \mathrm{~N}[6,7]$. Galliano et al. [7] observed an important reduction of $\mathrm{Al}$ and $\mathrm{V}$ concentrations in the compound layer with values near zero which is of interest for biomedical applications. Fernandes et al. [8] using Glow Discharge Optical Emission Spectroscopy (GDOS) obtained chemical depth profiles for Ti6Al4V samples nitrided for $14 \mathrm{~h}$ at $600{ }^{\circ} \mathrm{C}$ and for $12 \mathrm{~h}$ at $700{ }^{\circ} \mathrm{C}$ in a $\mathrm{N}_{2}-\mathrm{H}_{2}(50-50 \%)$ atmosphere. A

\footnotetext{
* Corresponding authors. Tel.: +55 5133089404

E-mail addresses: tmanhabosco@yahoo.com.br (T.M. Manhabosco), ilmuller@ ufrgs.br (I.L. Müller).
}

nitride layer of about $0.25 \mu \mathrm{m}$ at $600{ }^{\circ} \mathrm{C}$ and $0.7 \mu \mathrm{m}$ at $700{ }^{\circ} \mathrm{C}$ was detected with very low concentrations of $\mathrm{Al}$ and $\mathrm{V}$ atoms.

Biomaterials introduced in the human body are frequently exposed to simultaneous chemical/electrochemical and mechanical stresses i.e., to tribocorrosion. According to Landolt et al. [9], tribocorrosion is an irreversible transformation of a material resulting from simultaneous physicochemical and mechanical surface interactions taking place in a tribological contact. Under these conditions, the material degradation rate cannot be evaluated by independent corrosion or mechanical experiments, since, in several situations, corrosion degradation is favoured by the mechanical action and vice versa [9-12]. Galliano et al. [7] investigated the tribocorrosion behaviour of plasma nitrided Ti6Al4V alloy in a $0.9 \mathrm{M} \mathrm{NaCl}$ solution. They observed that samples nitrided at $1173 \mathrm{~K}$ which presented a thicker compound layer than that nitrided at $973 \mathrm{~K}$ presented better tribocorrosion resistance.

Considering the commercial importance of the Ti6Al4V alloy as a biomaterial, the purpose of the present work is to help elucidate the behaviour of both the bare and the nitrided alloy, in conditions where corrosion and wear act independently comparing the results with those in tribocorrosion situation, using PBS as an inorganic solution trying to simulate the corrosiveness of the body fluids.

\section{Experimental details}

The samples used were Ti6A14V alloy (Gr.5) disks, $38 \mathrm{~mm}$ in diameter and $17 \mathrm{~mm}$ thick, with a composition specified in Table 1 . The samples were ground with successively finer grit of $\mathrm{SiC}$ until 800 and polished with colloidal silica to a surface 
Table 1

Composition of Ti6Al4V according supplier.

\begin{tabular}{ll}
\hline Element & Composition (wt.\%) \\
\hline $\mathrm{N}$ & 0.004 \\
$\mathrm{C}$ & 0.004 \\
$\mathrm{H}$ & 0.0022 \\
$\mathrm{Fe}$ & 0.04 \\
$\mathrm{O}$ & 0.117 \\
$\mathrm{Al}$ & 5.97 \\
$\mathrm{~V}$ & 4.03 \\
$\mathrm{Ti}$ & Balance \\
\hline
\end{tabular}

roughness of about Ra $0.025 \mu \mathrm{m}$. After polishing, the samples were ultrasonically cleaned in acetone for $10 \mathrm{~min}$ followed by rinsing in methanol and deionised water.

Some samples were nitrided in a gas mixture of $10 \% \mathrm{Ar}, 50 \% \mathrm{H}_{2}$ and $40 \% \mathrm{~N}_{2}$ at $300 \mathrm{~Pa}$ for $10 \mathrm{~h}$. The temperature of the process $(1073 \mathrm{~K})$ was chosen below the transition temperature of the alloy (1228 K). Sample cross-sections were etched (Kroll's reagent) and analyzed by scanning electron microscopy (SEM - LEO - SUPRA 35, Gemini). Microhardness profiles were obtained using a Vickers indenter with a load of $25 \mathrm{~g}$ for $15 \mathrm{~s}$ (MTH-4 microhardness tester attached to an Olympus microscope). The nitrided layer microstructure was analyzed by X-ray diffraction (X Philips - X́Pert MRD) with $\mathrm{Cu} \mathrm{K} \alpha$ radiation $(\lambda=1,5406 \AA)$.

The corrosion behaviour of the bare and nitrided alloy was evaluated by polarization curves, potentiostatic corrosion tests and electrochemical impedance spectroscopy (EIS) measurements. Impedance data for $1 \mathrm{~h}, 24 \mathrm{~h}, 48 \mathrm{~h}, 7$ days, 16 days, 23 days and 30 days of immersion were acquired by a potentiostat (AUTOLAB PGSTAT 30) and a frequency response analyzer (FRA) system operating at open circuit potential (OCP) in a frequency range from $100 \mathrm{kHz}$ to $3 \mathrm{mHz}$ with a perturbation of $\pm 10 \mathrm{mV}$. Potentiodynamic polarization curves were performed at a scan rate of $0.167 \mathrm{mV} / \mathrm{s}$ using an EG\&G 273A potentiostat. The same potentiostat was used for potentiostatic tests at $400 \mathrm{mV}_{\mathrm{SCE}}$, an anodic potential located in the passive region of the alloy. All tests were carried out in a three-electrode cell containing phosphate buffer saline (PBS) solution at $37^{\circ} \mathrm{C}\left( \pm 1^{\circ} \mathrm{C}\right)$ in order to simulate the body environment. The solution $(\mathrm{pH}=7.1)$ is composed by $8 \mathrm{~g} \mathrm{~L}^{-1} \mathrm{NaCl} ; 0.2 \mathrm{~g} \mathrm{~L}^{-1} \mathrm{KCl} ; 0.594 \mathrm{~g} \mathrm{~L}^{-1} \mathrm{Na}_{2} \mathrm{HPO}_{4}$ and $0.2 \mathrm{~g} \mathrm{~L}^{-1} \mathrm{KH}_{2} \mathrm{PO}_{4}$. A saturated calomel reference electrode was used as reference electrode and a platinum (Pt) wire as counter electrode.

Wear tests were carried out in a computer-controlled reciprocating motion pin-on-plate tribometer, using an alumina ball ( $\varnothing$ $5 \mathrm{~mm}$, Saphirwerk). These tests were performed by setting normal load, sliding velocity and sliding distance to $4 \mathrm{~N}, 8 \mathrm{~mm} / \mathrm{s}$, and $8 \mathrm{~mm}$, respectively.

Tribocorrosion tests were achieved coupling the electrochemical cell to the pin-on-plate tribometer with the saturated calomel reference electrode no more than $1 \mathrm{~cm}$ distant from the wear track. The electrochemical and wear parameters for tribocorrosion tests were the same as used in single electrochemical and wear tests in order to verify a possible increase of degradation due to the simultaneous action of corrosion and wear mechanisms. It is important to point out that the moving part during tests was not the alumina ball but the sample together with the electrochemical cell.

After each test involving wear action, the wear track was analyzed by SEM and its profile was acquired by profilometry (MicroGlider, Fries Research \& Technology).

\section{Results and discussion}

\subsection{Characterization of nitrided samples}

According to profilometric measurements the mean initial roughness ( $\mathrm{Ra}$ ) of $25 \mathrm{~nm}$ for Ti6Al4V increases to $150 \mathrm{~nm}$ after nitriding due to the sputtering process for oxide removal and the plasma interaction with the activated sample surface. Rahman et al. [13] observed that the nitriding temperature plays a major role in surface roughness and the higher this temperature the higher the roughness of the nitrided sample due to plasma interaction with the active sample surface containing $\beta$ phase. Visually the grey coloured Ti6Al4V samples become gold-like after nitriding processes.

A SEM image of a cross-sectioned sample chemically etched with Kroll's reagent is presented in Fig. 1. The presence of a compound layer about $1 \mu \mathrm{m}$ thick can be clearly observed. X-ray diffraction (XRD) analysis confirmed the presence of $\mathrm{Ti}_{2} \mathrm{~N}$ (tetragonal) and TiN (CFC) phases in the compound layer (Fig. 2).

Microhardness profiles are very suitable to evaluate the extent of the nitrogen diffusion into the sample. The literature reports that higher nitriding temperature increases not only hardness but also roughness of the material $[8,13]$. Time also plays an important role in the hardness of the nitrided samples [4]. Fig. 3 shows a mean hardness profile indicating a value of about 605 HV near the surface due to the compound layer observed by SEM, consisting of nitrides as verified by XRD. The higher disper-

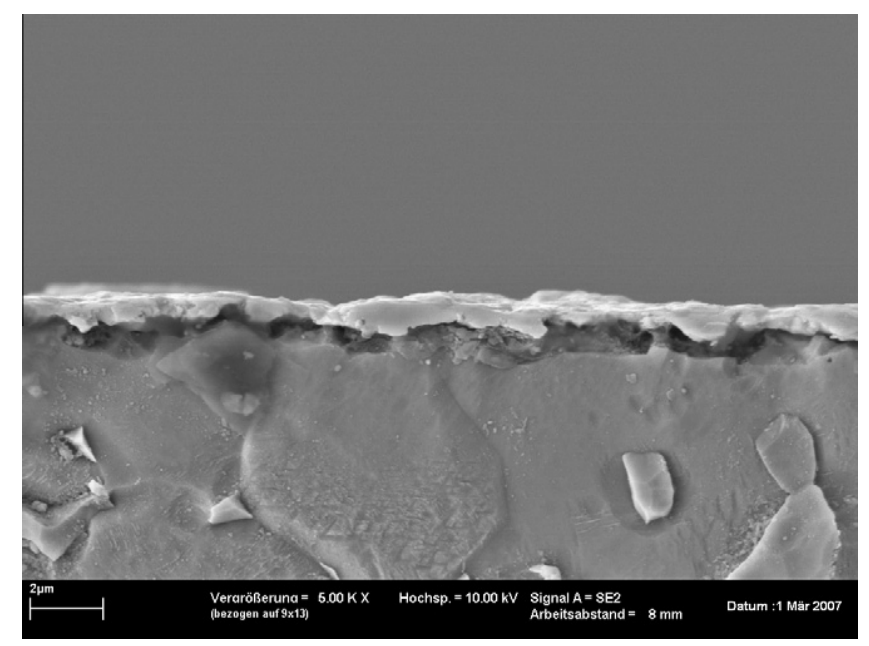

Fig. 1. SEM image of cross-sectioned Ti6Al4V plasma nitrided layer etched with Kroll's reagent.

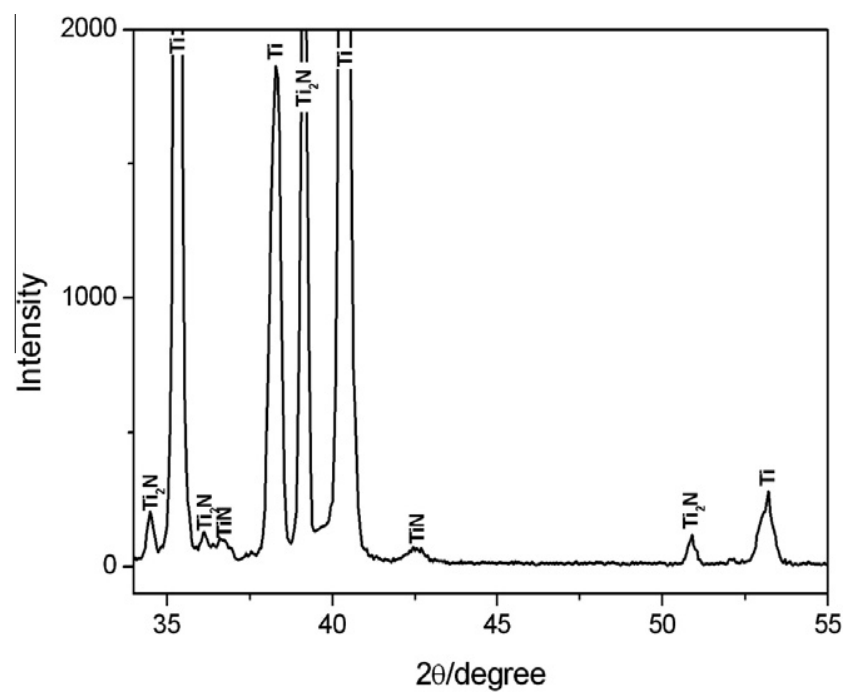

Fig. 2. X-ray diffraction pattern of Ti6Al4V plasma-nitrided sample. 


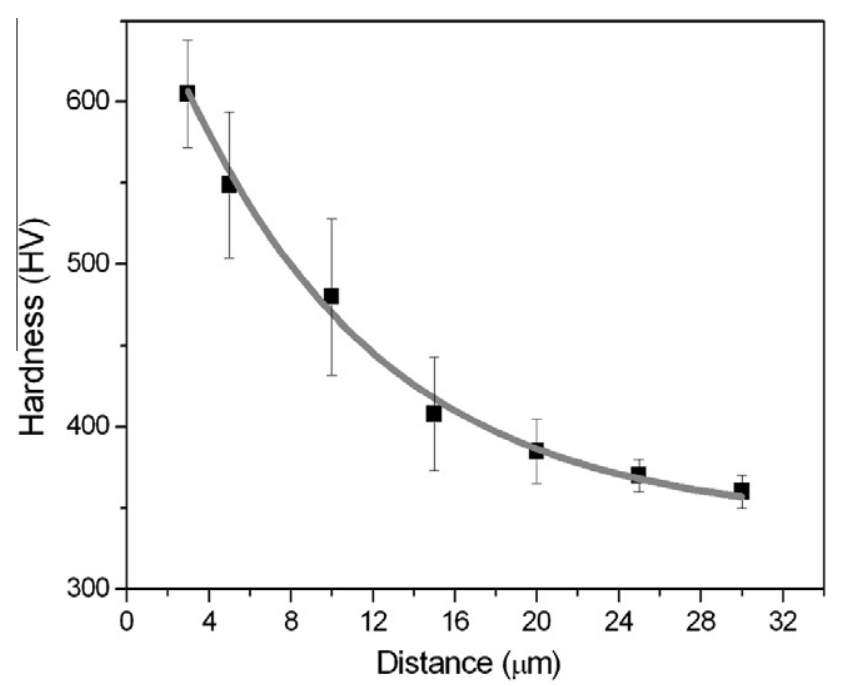

Fig. 3. Microhardness profile of cross-sectioned Ti6Al4V plasma nitrided sample. Bars indicate the measurements dispersion.

sion of the values measured near the surface reflects the heterogeneity of this region. A decrease of the hardness is observed along the diffusion zone approaching the base matrix microhardness about $30 \mu \mathrm{m}$ from the surface.

\subsection{Corrosion behaviour studies}

Fig. 4 shows the potentiodynamic polarization curves in PBS solution for the bare and the nitrided alloy. The bare alloy showed a passive behaviour due to the formation of a protective oxide layer, with low anodic current densities $\left(0.8 \mu \mathrm{A} / \mathrm{cm}^{2}\right)$ in a wide range of potentials (from 0 to $1.6 \mathrm{~V}_{\mathrm{SCE}}$ ). After nitriding, the corrosion potential of the alloy changed from -0.35 to $+0.24 \mathrm{~V}_{\mathrm{SCE}}$, and lower anodic current densities than for the bare alloy were found until $0.75 \mathrm{~V}_{\mathrm{SCE}}$, indicating an increase in the corrosion resistance, probably associated with the formation of the compound layer composed by $\mathrm{TiN}$ and $\mathrm{Ti}_{2} \mathrm{~N}$ and/or to the enrichment of the metallic matrix in nitrogen. Low anodic current densities about $1.5 \mu \mathrm{A} / \mathrm{cm}^{2}$ are found until $1.1 \mathrm{~V}_{\mathrm{SCE}}$ and afterwards there is an anodic peak. According to the Pourbaix diagram proposed by Heide and Schultze [14] the anodic peak may correspond to the oxidation of TiN to $\mathrm{TiO}_{2}$.

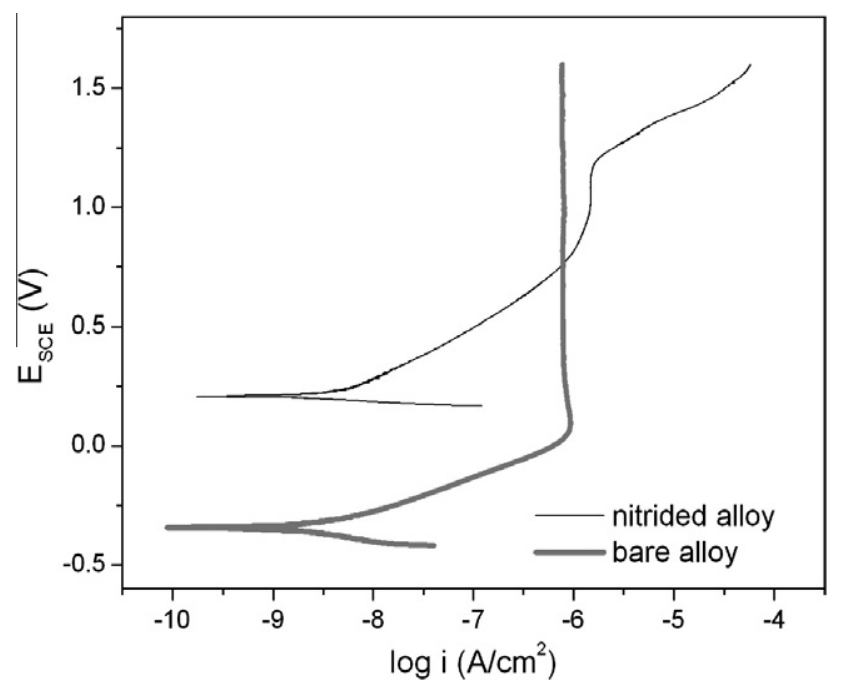

Fig. 4. Potentiodynamic polarization curves in PBS solution for untreated and nitrided alloy. Sweep rate: $0.167 \mathrm{mV} / \mathrm{s}$.
EIS experiments obtained at open circuit potential (OCP) in PBS solution were performed to characterize both the bare and nitrided Ti6Al4V samples. Figs. 5-7 show the Bode and Nyquist plots of experimental and fitted data of the alloy under both conditions, for increasing immersion times, namely $1 \mathrm{~h}, 16$ days, and 23 days in PBS solution, respectively. The nitrided sample shows a different behaviour due to the absence of the surface titanium oxide layer and the presence of titanium nitrides with high chemical inertia. The high impedance values and phase angle of almost $-90^{\circ}$ at intermediate frequencies are indicative of a near capacitive response related to surface titanium nitrides, evidenced metallographically (Fig. 1) and by the X-ray data shown in Fig. 2. Moreover, after 23 days of immersion in PBS solution a still very high total impedance $\left(>5 \mathrm{M} \Omega \mathrm{cm}^{-2}\right.$ ) confirms the low reactivity of the nitride alloy.

The results for bare samples can be interpreted in terms of two time constants overlapped for a broad frequency range, as also reported in recent works [15-17]. The electrochemical behaviour for bare Ti6Al4V was modelled by the equivalent circuit $R_{1}\left(Q_{\mathrm{p}}\left(R_{\mathrm{p}}\left(R_{\mathrm{g}} \mathrm{Q}_{\mathrm{g}}\right)\right.\right.$ which is composed by circuit elements: $R_{1}$, representing the solution ohmic resistance between the working and the reference electrodes, $Q$ element, which represents a constant phase element (CPE) and describes a non-ideal capacitor when the capacitor phase angle is different from $-90^{\circ}$ [18]. CPE impedance is generally attributed to distributed surface reactivity, surface heterogeneity and roughness, to current and potential distribution related to the electrode geometry and porosity [19]. $Q_{\mathrm{p}}$ and $\mathrm{Q}_{\mathrm{g}}$ are associated, respectively with a more internal passive oxide layer and a more external porous layer on Ti6Al4V alloy. The circuit element $R_{\mathrm{P}}$, corresponds to the polarization resistance which is related to the resistance of the barrier layer composed by the oxide film on the alloy, promoting high corrosion resistance at the metal/oxide film interface. $R_{\mathrm{g}}$ stands for the resistance of the more porous oxide layer at the top of the alloy.

Circuit $R_{1}\left(Q_{\mathrm{p}} R_{\mathrm{p}}\right)$ was proposed for simulating EIS data of nitrided samples, as also proposed in recent work [17]. The values of equivalent circuit elements resulting from simulation by the Autolab software are shown in Table 2 for both samples. The lower $R_{\mathrm{p}}$ values, associated with resistance of the oxide barrier layer of the Ti alloy, when compared to $R_{\mathrm{p}}$ values, related to the nitrided layer on the alloy for all immersion times tested, are to be attributed to a higher corrosion resistance for the nitrided alloy in this medium. The phase-angle profiles in the low frequency region in Fig. 5(B), 6(B) and 7(B) confirm the predominant capacitive contribution on nitrided samples, maintaining high $\theta$ values for frequencies much lower than for the untreated alloy. All these features point to a higher corrosion resistance of the nitrided samples than of the untreated samples.

It can be observed that the untreated alloy shows an increase of $R_{\mathrm{p}}$ values at 1 day (as compared with the initial value at $1 \mathrm{~h}$ of immersion), and it is plausible to assume that it is related to an increase of the oxide thickness with time, according to previous works [15,16], which is also consistent with the elevation of the OCP values observed. Nevertheless after 23 days some decrease in the $R_{\mathrm{p}}$ value is observed, probably associated with a modification of the oxide in the solution.

\subsection{Tribological behaviour studies}

Fig. 8 presents the friction coefficients obtained from computationally controlled reciprocating ball-on-plate wear tests performed at $4 \mathrm{~N}$, sliding velocity of $8 \mathrm{~mm}$ and $8 \mathrm{~mm}$ track length. For bare alloy a run-in period is observed corresponding to the initial sliding process between two polished surfaces followed by an oscillation around a mean value of 0.38 . The oscillations are due to the introduction and entrapping of a large amount of particles 



Fig. 5. Bode and Nyquist plots of experimental data of bare $(\boldsymbol{\square})$ and nitrided $(\bigcirc)$ alloy after $1 \mathrm{~h}$ of immersion in PBS solution. Fitted data included as dashed lines.
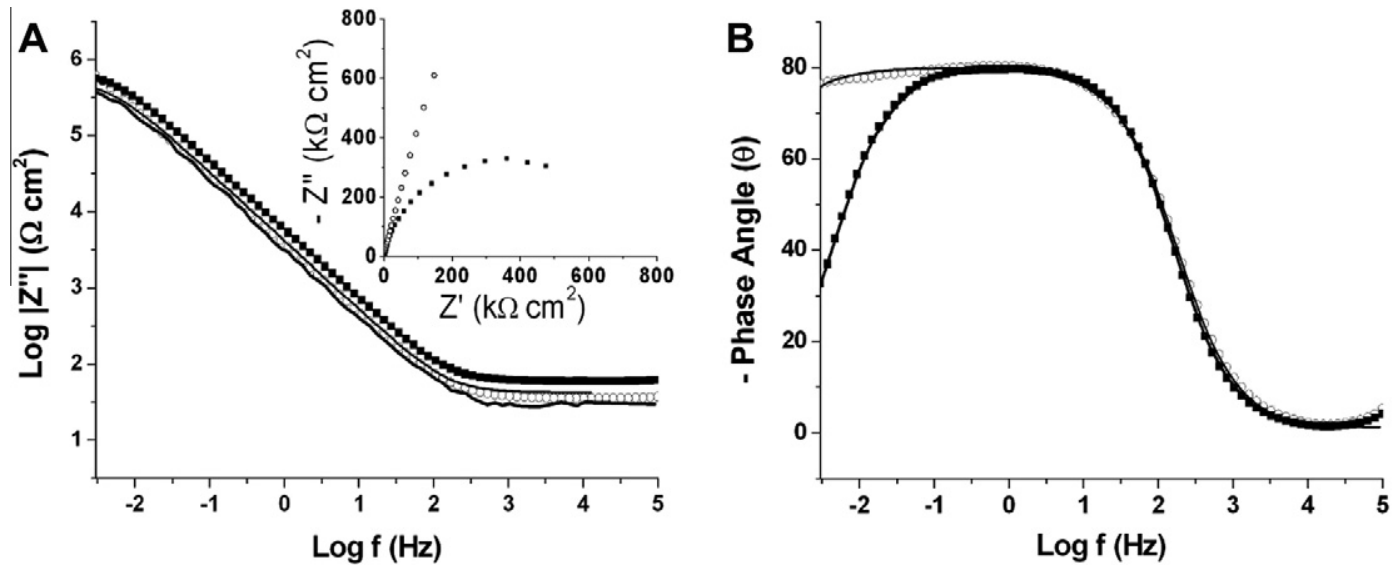

Fig. 6. Bode and Nyquist plots of experimental data of bare $(\boldsymbol{\square})$ and nitrided $(\bigcirc)$ alloy after 1 day of immersion in PBS solution. Fitted data included as dashed line.
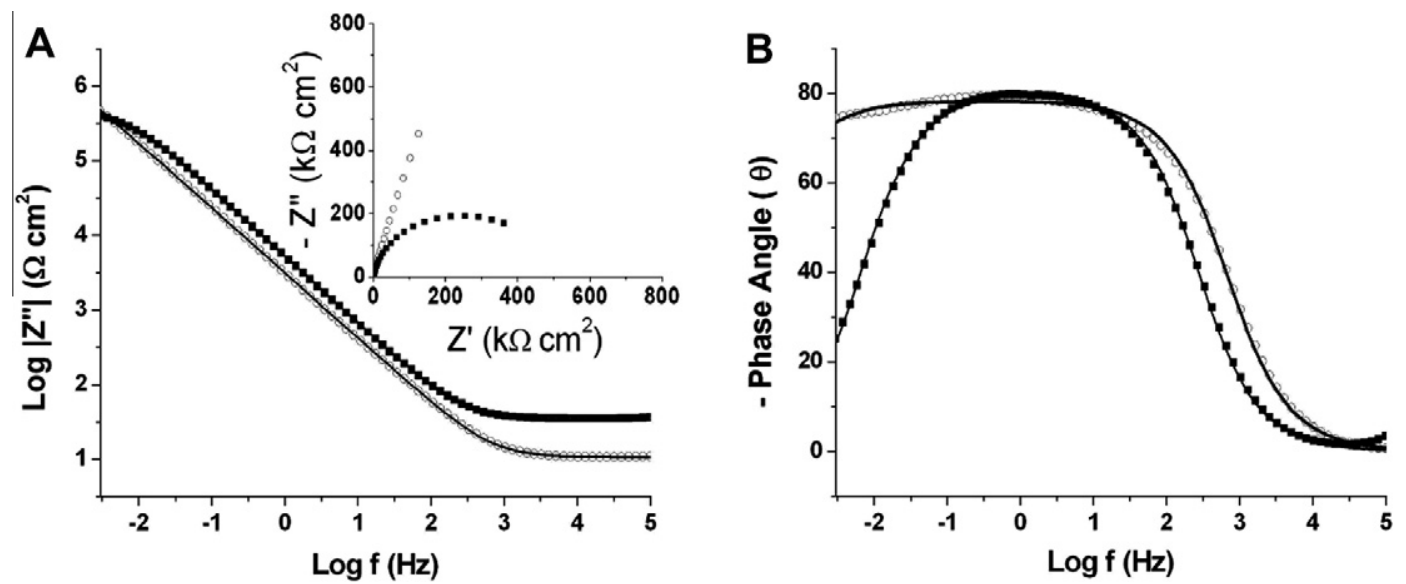

Fig. 7. Bode and Nyquist plots of experimental data of bare ( $\boldsymbol{\square})$ and nitrided $(\bigcirc)$ alloy after 23 days of immersion in PBS solution. Fitted data included as dashed line.

(third body) in the contact region as a consequence of higher wear rates. In order to investigate the influence of the worn out material and of the entrapped third body on the friction coefficient, several tests were carried out, and the particles were removed after the wear test had been running for some time. The particle removal lowers the friction coefficient and its oscillations. The friction coefficient increases again and oscillates as the test goes on and new particles are introduced in the contact region. Friction coefficients acquired from tests with nitrided alloy also present a run-in period characterized by its increase induced by asperity surface wear and consequent particle introduction into the contact region. After the run-in period the friction coefficient oscillates around a mean value of 0.41 . The oscillations are lower than those observed for the bare alloy as the nitrided alloy has higher hardness and produces a smaller amount of entrapped particles.

Wear track profiles were acquired for bare and nitrided specimens after same condition tests and were used to calculate wear track volumes of $1.2 .10^{-10} \mathrm{~m}^{3}$ and $2.4 .10^{-13} \mathrm{~m}^{3}$, respectively, corresponding to a reduction of approximately 900 times in the wear volume of nitrided samples. Wear track SEM images for bare 
Table 2

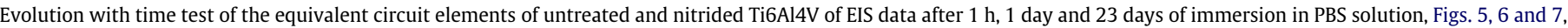
respectively.

\begin{tabular}{|c|c|c|c|c|c|c|c|c|}
\hline Samples & Immersion time & $E_{\text {corr }}\left(\mathrm{mV}_{\mathrm{SCE}}\right)$ & $R_{1}\left(\Omega \mathrm{cm}^{2}\right)$ & $Q_{P}\left(\mu \mathrm{F} \mathrm{cm}^{-2}\right)$ & $\mathrm{n}$ & $R_{\mathrm{P}}\left(\mathrm{k} \Omega \mathrm{cm}^{2}\right)$ & $C_{\mathrm{g}}\left(\mu \mathrm{F} \mathrm{cm}^{-2}\right)$ & $R_{\mathrm{g}}\left(\mathrm{k} \Omega \mathrm{cm}^{2}\right)$ \\
\hline Bare Ti6Al4V & $1 \mathrm{~h}$ & -83 & 64 & 32 & 0.89 & 1430 & 1.2 & 245 \\
\hline Nitrided Ti6Al4V & $1 \mathrm{~h}$ & -41 & 19 & 78 & 0.89 & 8900 & - & - \\
\hline Bare Ti6Al4V & 1 day & +48 & 59 & 30 & 0.89 & 1639 & 2.42 & 1470 \\
\hline Nitrided Ti6Al4V & 1 day & -19 & 35 & 51 & 0.89 & 6960 & - & - \\
\hline Bare Ti6Al4V & 23 days & +86 & 35 & 37 & 0.88 & 464 & 36 & 463 \\
\hline Nitrided Ti6Al4V & 23 days & +31 & 11 & 64 & 0.87 & 5520 & - & - \\
\hline
\end{tabular}

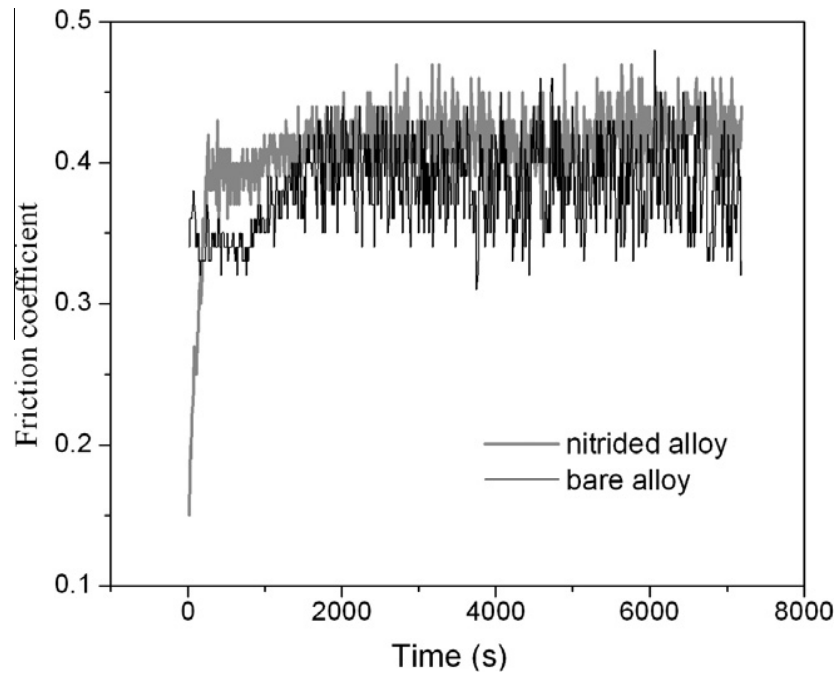

Fig. 8. Friction coefficient for bare and nitrided alloy in dry conditions.

alloy (Fig. 9(A)) shows a large amount of strained material in the wear track and extruded material toward the edge of contact. The fractured junctions produced hard particles that were trapped between the contacting surfaces, causing ploughing. Wear and transfer of material is observed to the counterbody, which ultimately injects high hardness particles into the contact region. From the analysis it can be concluded that the bare alloy suffered asperity deformation, adhesive and abrasive wear as also verified by other authors $[20,21]$.

Nitrided alloy (Fig. 9(B)) showed a narrow, smooth and shallow wear track with an expressive reduction of wear debris. No clear transferred layer could be observed on the alumina counterbody due to the absence of an adhesive wear mechanism. No ploughing line or severe deformation in the wear track can be seen due to the greater hardness of the nitrided layer, indicating that the nitriding process increases the tribological properties of the alloy.

\subsection{Tribocorrosion studies}

\subsubsection{Potentiodynamic tests}

Potentiodynamic polarization curves were acquired at the same time as wear occurred and the results are presented in Fig. 10 for untreated and nitrided alloy, respectively.

It can be clearly observed that under wear-corrosion conditions there was a change in the corrosion and tribological characteristics. Bare alloy presents a lowering in the corrosion potential and higher current densities due to the continuous removal of the surface passive film. When the alumina ball wears the surface, the passive oxide film is locally destroyed exposing the alloy to fresh electrolyte and causing a lowering of the corrosion potential as verified in other similar systems $[8,12,22,23]$. Despite the passive layer removal with some possible incipient dissolution, no corrosive process follows due to the rapid repassivation, as deduced from current density oscillations. Such oscillations in potentiodynamic curves were also observed by Neville and McDougall [24] under liquid-solid impingement conditions due to the impacting sand and the depassivation/repassivation events occurring over a small region of the material.

Nitrided alloy also presented a lower corrosion potential as the wear mechanism produces a more active surface in the wear track. According to Galliano et al. [7] the active surface could be related to the external oxide or oxynitride film removal. During scanning in the positive potential direction some oscillations take place after $0.3 \mathrm{~V}_{\mathrm{SCE}}$, however; they are different from that presented by bare alloy. This behaviour may be related to mechanical behaviour of the fragile compound layer that may break locally exposing more active metallic regions that could be covered again as wear continues. However, crevice corrosion under coating debris and/or microcracks cannot be excluded.

Fig. 11(A) and (B) presents plotted friction coefficient and $\log i$ versus time for bare and nitrided alloy. No influence could be observed of electrochemical reactions on the friction coefficient for bare alloy that presents a lower mean value (0.34) compared to the dry conditions due to the lubricant action of water. It is verified for nitrided alloy that when anodic processes take place,
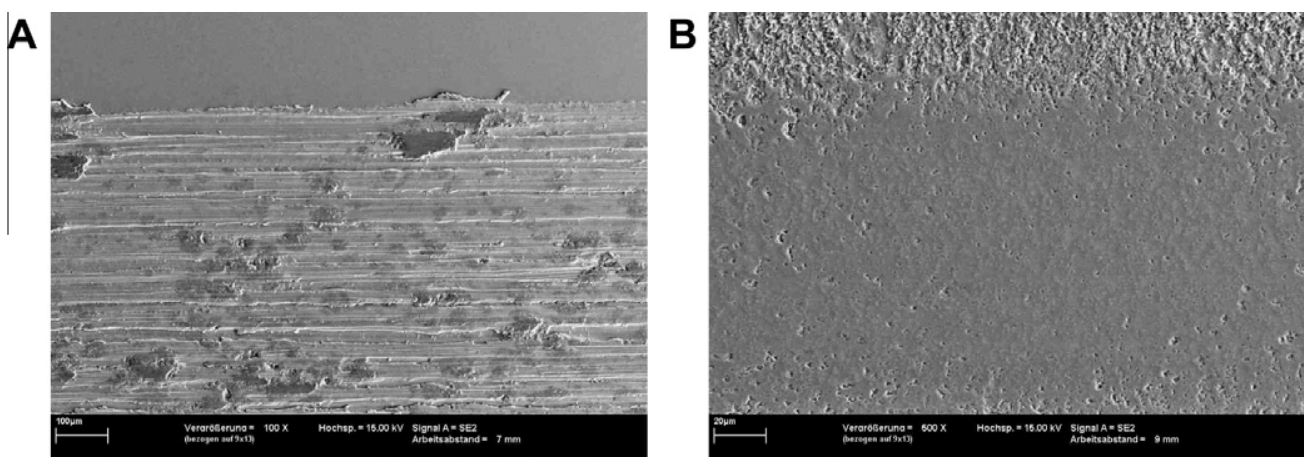

Fig. 9. SEM images of the wear track for bare (A) and nitrided alloy (B) after dry wear tests at $4 \mathrm{~N}$ normal load, sliding velocity of $8 \mathrm{~mm} / \mathrm{s}$ and $8 \mathrm{~mm}$ sliding distance. 


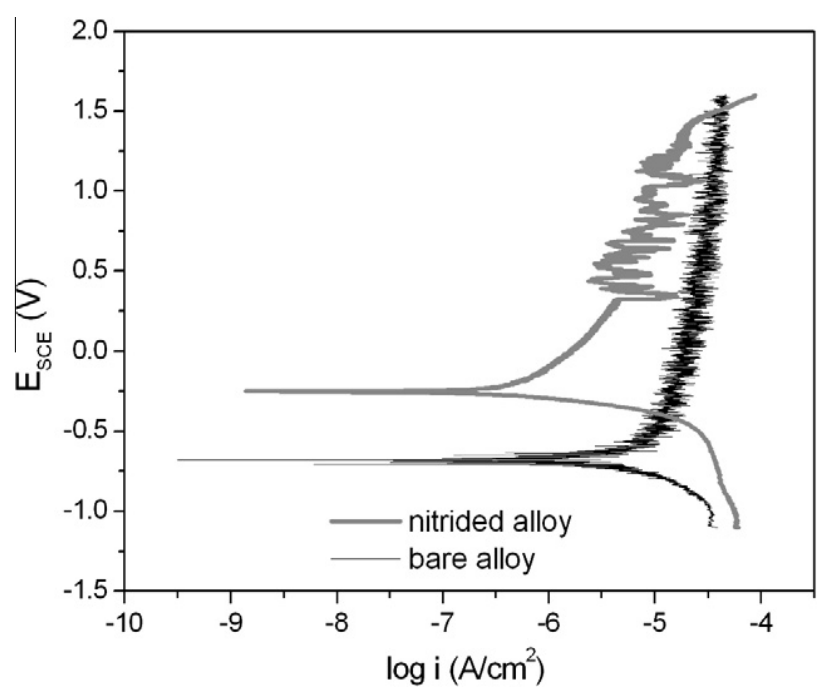

Fig. 10. Potentiodynamic polarization curves in PBS solution for bare and nitrided Ti6Al4V with simultaneous wear at $4 \mathrm{~N}$ normal load, sliding velocity of $8 \mathrm{~mm} / \mathrm{s}$ and $8 \mathrm{~mm}$ sliding distance. Potential sweep rate: $0.167 \mathrm{mV} / \mathrm{s}$.

the friction coefficient increases up to a maximum, indicating the occurrence of surface modifications due to the corrosive conditions, which influences the friction coefficient. The oscillations in friction coefficient correspond to simultaneous oscillations in anodic current clearly showing the synergistic effect of corrosion and wear mechanisms. Despite the interesting information acquired using this technique, it is important to keep in mind that the nitrided layer is continuously worn away during the test and at each potential a new and different surface is exposed to wear.

\subsubsection{Corrosion potential tests}

Open circuit potentials for bare and nitrided alloy were monitored before and during mechanical wear with the same mechanical parameters used in potentiodynamic tests and they are presented in Fig. 12. The beginning of mechanical wear is indicated by a dotted vertical line.

At the onset of mechanical wear, the OCP abruptly goes to more negative values in agreement with the potentiodynamic curves. The bare alloy potential oscillations are due to rapid repassivation after mechanical wear, i.e. depassivation/repassivation events. EIS measurements confirmed the alloy tendency to increase protection with time by oxide growing, according to other previous works on corrosion behaviour of passivable metals [17]. The nitrided alloy does not present important potential oscillations probably due to

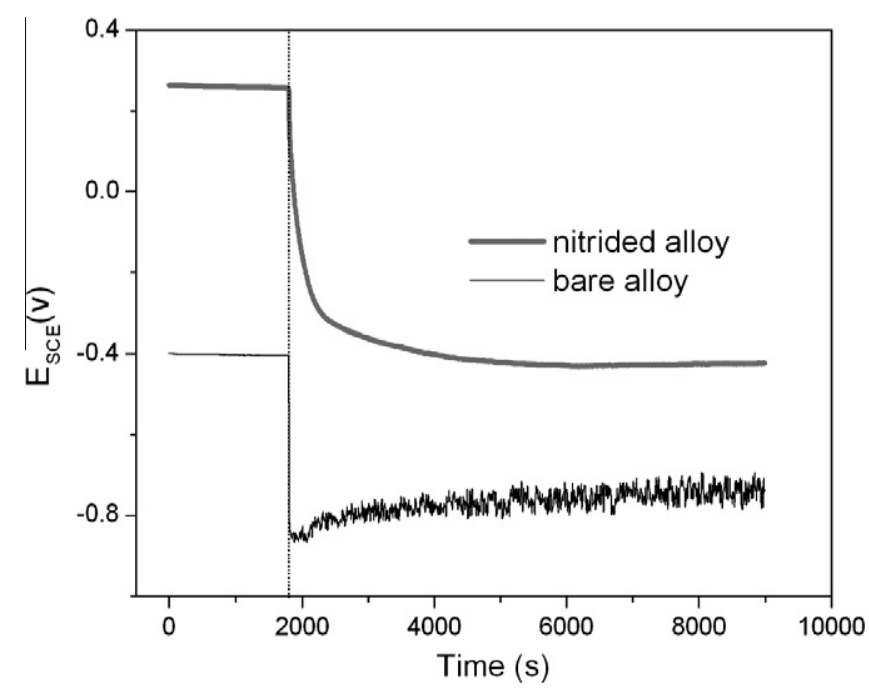

Fig. 12. Open circuit potential monitoring for bare and nitrided alloy before and during the wear at $4 \mathrm{~N}, 8 \mathrm{~mm} / \mathrm{s}$ and $8 \mathrm{~mm}$. A doted vertical line indicates the onset of wear.

the exposure of a very stable compound layer to electrolyte, the absence of an accelerated corrosion process in this layer and a lower removal of the top layer as it presents a high hardness and electrochemical stability in this environment. SEM image (Fig. 13) and depth profiles for bare alloy after OCP tests indicate changes in the wear track morphology: it is narrower, deeper and less rough than that observed in dry wear conditions thus resulting in a lower wear volume $\left(0.94 .10^{-10} \mathrm{~m}^{3}\right)$. This is possibly due to a smaller amount of entrapped third body since in presence of the liquid phase particles are easily dispersed in the solution. Wear tracks on nitrided samples were very similar to those of dry conditions, indicating a fair stability of the nitrided layer at tested conditions in agreement with electrochemical results. As verified, tribological data are not properties related to a single material but to a tribosystem, involving counterbody material, testing conditions, environment and so forth [25-27].

\subsubsection{Potentiostatic tests}

Potentiostatic corrosion tests were performed at $0.4 \mathrm{~V}_{\mathrm{SCE}}$ with simultaneous wear and the results $i \times t$ and friction coefficient $\times t$ are presented in Fig. 14 for bare (A) and nitrided samples (B). Results of single corrosion tests at $0.4 \mathrm{~V}_{\mathrm{SCE}}$ are inserted in the graphics for comparison. As expected, higher current densities and oscillations are observed for the bare alloy. In absence of wear, $i$
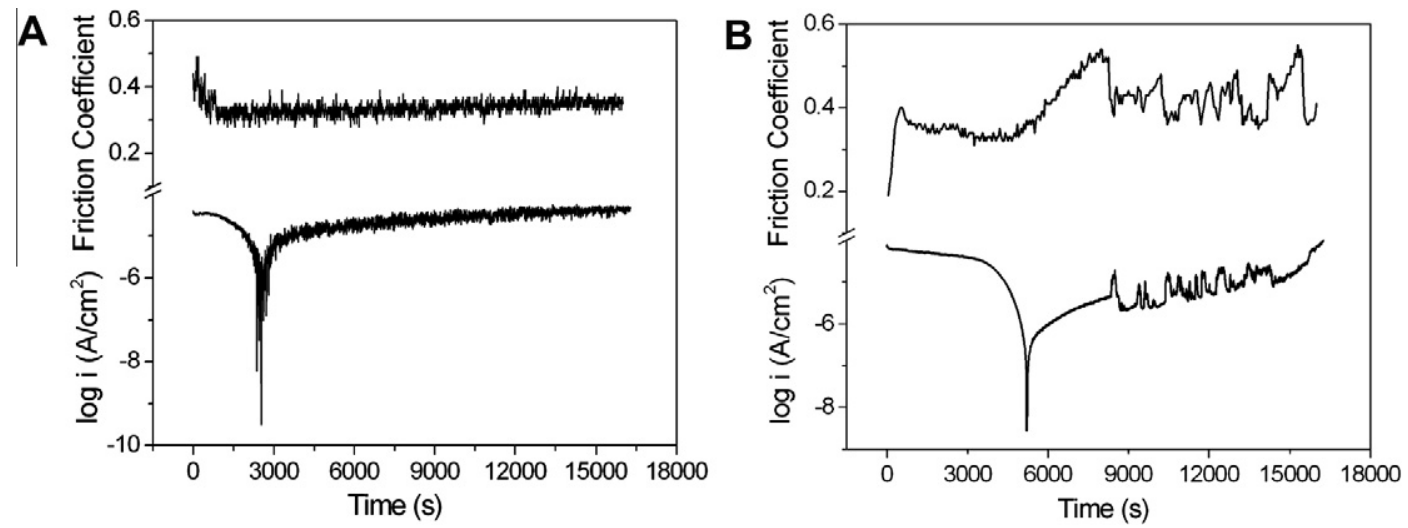

Fig. 11. Friction coefficient and $\log i$ versus time for untreated and nitrided alloy obtained from simultaneous potentiodynamic polarization and wear. 


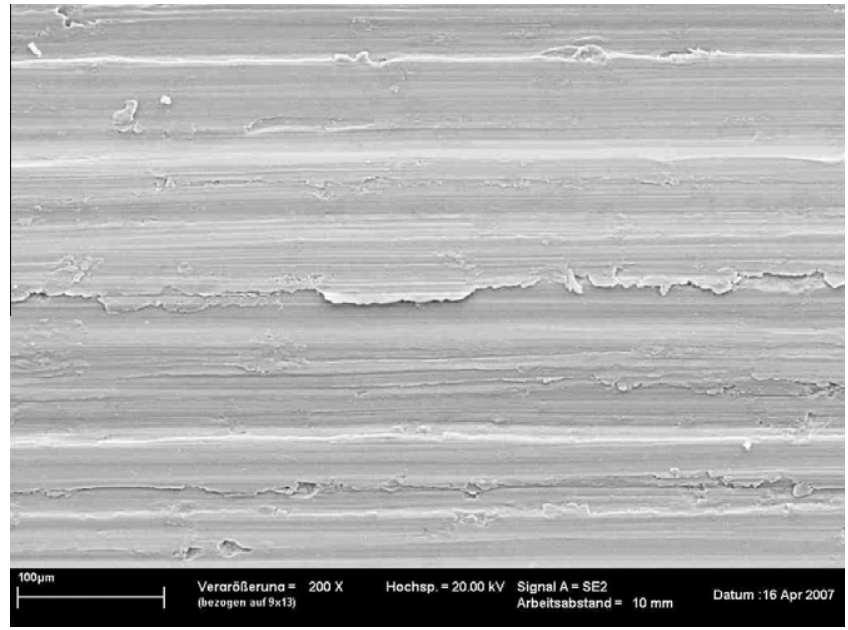

Fig. 13. SEM images of the wear track for bare alloy after wear-corrosion at OCP with a $4 \mathrm{~N}$ normal load, sliding velocity of $8 \mathrm{~mm} / \mathrm{s}$ and $8 \mathrm{~mm}$ sliding distance.

values are about $0.075 \mu \mathrm{A} / \mathrm{cm}^{2}$ that became $22 \mu \mathrm{A} / \mathrm{cm}^{2}$ due to the wear-corrosion process. For nitrided samples the current density was $0.016 \mu \mathrm{A} / \mathrm{cm}^{2}$ in absence of wear and goes up to the same value presented by bare alloy when wear and corrosion act simultaneously. The current increase in both cases clearly shows the influence of wear mechanisms over the corrosion process as already discussed.

Differently from the OCP tests with simultaneous wear, the influence of an applied anodic potential of $0.4 \mathrm{~V}_{\text {SCE }}$ could be observed on the friction coefficient results (Fig. 14) for the nitrided alloy. Friction coefficient shows a run-in period followed by an increase of up to $2000 \mathrm{~s}$ accompanied by an important increase of $i$ indicating that some superficial modification has taken place. This change could be related to removal and/or break of the nitride compound layer exposing the underlying alloy to the solution with consequent current increase. The subsequent decrease of $i$ could due to covering this region with an adjacent nitrided layer since the counter body performs a reciprocating motion. After this first event both friction coefficient and $i$ present corresponding variations. At the end of the tests the current densities are similar to that for bare alloy indicating a partial or total compound layer removal.

According to the calculated and experimental Pourbaix diagrams for TiN developed by Heide and Schultze [14], the nitride layer is stable in a long range of potentials and $\mathrm{pH}$, including OCP and $0.4 \mathrm{~V}_{\mathrm{SCE}}$ at $\mathrm{pH} 7.1$; however it should be kept in mind that



Fig. 15. Wear track profiles for bare and nitrided alloy after wear-corrosion tests at corrosion potential and $0.4 \mathrm{~V}_{\mathrm{SCE}}$ with a $4 \mathrm{~N}$ normal load, sliding velocity of $8 \mathrm{~mm} / \mathrm{s}$ and $8 \mathrm{~mm}$ sliding distance.

Pourbaix diagrams do not consider the simultaneous process of wear and corrosion that clearly promotes some instability in the system. These results show that for real tribocorrosion systems Pourbaix diagrams cannot predict the materials behaviour.

Fig. 15 presents the wear track profiles for bare and nitrided alloy after wear-corrosion tests at corrosion potential and $0.4 \mathrm{~V}_{\mathrm{SCE}}$. The analyses of wear track images after wear-corrosion tests at $0.4 \mathrm{~V}_{\mathrm{SCE}}$ for bare alloy indicate a similar morphology to that presented in wear-corrosion tests at OCP. The wear volume was just little higher $\left(1.0 .10^{-10} \mathrm{~m}^{3}\right)$ when applying the anodic potential. On the other hand, the influence of the applied potential $\left(0.4 \mathrm{~V}_{\mathrm{SCE}}\right)$ was more expressive for the nitrided alloy despite the much lower wear track volume $\left(1.2 .10^{-11} \mathrm{~m}^{3}\right)$ compared to bare alloy. The wear profile indicates an $8 \mu \mathrm{m}$ deep wear track pointing to the removal of the compound layer as expected from $i \times t$ graphics. It can be concluded from these tests that the applied nitriding process greatly increased the hardness and wear resistance of the alloy both in dry and wear-corrosion tests at OCP conditions. However wear-corrosion tests at $0.4 \mathrm{~V}_{\mathrm{SCE}}$ indicate just a reduction of approximately eight times in the wear track volume compared to that of bare alloy at the same tested conditions, i.e. the wear-corrosion resistance of the nitrided alloy at this anodic potential is greatly reduced.

It should be emphasized that the results obtained are limited to the present test conditions and their extrapolation to other wearcorrosion parameters may not be valid, as the contribution of each
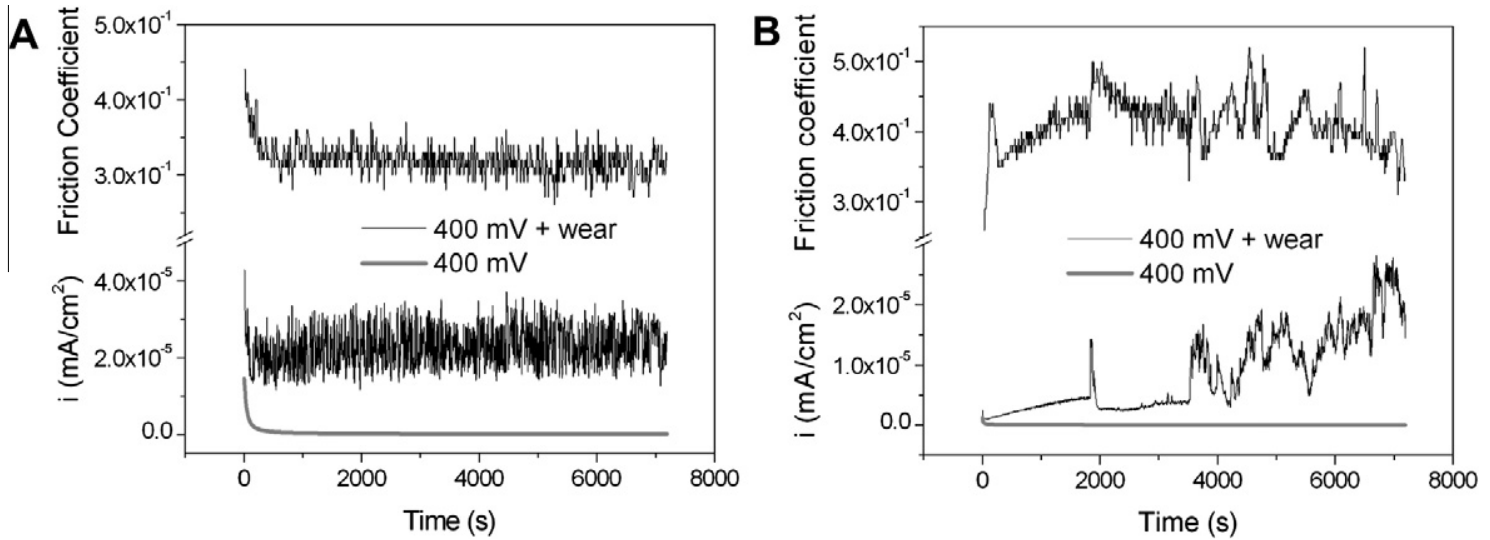

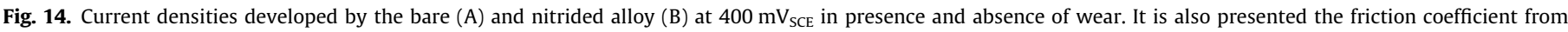
wear-corrosion tests. 
degradation mechanism to the overall degradation is also related to several other conditions as the used materials, apparatus and operation, the mechanical and electrochemical solicitations. Further experiments are needed to map the behaviour of this alloy under different conditions to clearly understand the interaction between mechanical and electrochemical aspects of degradation, aiming to better adapt materials to their use in biomedical applications.

\section{Conclusions}

Passive oxide provides good corrosion protection for Ti6Al4V in PBS. This is enhanced over time due to the growth of the compact oxide film as inferred from the elevation of the OCP and confirmed by EIS measurements, corroborating the excellent corrosion resistance of the alloy. When this oxide is damaged by wear, the alloy presents a great tendency to repassivate which is useful for biomedical applications. The results of EIS highlight the interest in producing a nitrided layer by PVD directly on the Ti6Al4V alloy, since this layer enhances the anticorrosion properties in PBS solution.

Nitriding the alloy promotes a major increase in surface hardness and wear resistance in dry conditions. The nitrided alloy also shows a significant increase in wear-corrosion behaviour at corrosion potential. However, wear-corrosion tests at $0.4 \mathrm{~V}_{\mathrm{SCE}}$ indicate that anodic potentials impair the increased tribocorrosion resistance offered by the nitride layer at the corrosion potential.

\section{Acknowledgments}

The authors are grateful to the Brazilian government agencies CAPES and CNPq for supporting the present research and to the Fraunhofer Institute (Stuttgart - Germany) for allowing the wear tests and SEM analysis.

\section{References}

[1] M. Niinomi, Mechanical properties of biomedical titanium alloys, Mater. Sci Eng. A 243 (1998) 231-236.

[2] M.A. Khan, R.L. Williams, D.F. Williams, In-vitro corrosion and wear of titanium alloys in the biological environment, Biomaterials 17 (1996) 2117-2126.

[3] B.L. Gabriel, J. Gold, A.G. Gristina, B. Kasemo, J. Lausmaa, C. Harrer, Q.N. Myrvik, Site-specific adhesion of Staphylococcus epidermidis (RP12) in Ti-A1-V metal systems, Biomaterials 15 (1994) 628-634

[4] A. Zhecheva, W. Sha, S. Malinov, A. Long, Enhancing the microstructure and properties of titanium alloys through nitriding and other surface engineering methods, Surf. Coat. Technol. 200 (2005) 2192-2207.

[5] P. Kaestner, J. Olfe, J.W. He, K.-T. Rie, Improvement in the load-bearing capacity and adhesion of TiC coatings on TiAl6V4 by duplex treatment, Surf. Coat. Technol. 142-144 (2001) 928-933.
[6] F. Yildiz, A.F. Yetim, A. Alsaran, A. Çelik, Plasma nitriding behavior of Ti6Al4V orthopaedic alloy, Surf. Coat. Technol. 202 (2007) 2471-2476.

[7] F. Galliano, E. Galvanetto, S. Mischler, D. Landolt, Tribocorrosion behavior of plasma nitrided Ti-6Al-4V alloy in neutral $\mathrm{NaCl}$ solution, Surf. Coat. Technol. 145 (2001) 121-131.

[8] A.C. Fernandes, F. Vaz, E. Ariza, L.A. Rocha, A.R.L. Ribeiro, A.C. Vieira, J.P. Rivière, L. Pichon, Tribocorrosion behaviour of plasma nitrided and plasma nitrided + oxidised Ti6Al4V alloy, Surf. Coat. Technol. 200 (2006) 6218-6224.

[9] D. Landolt, S. Mischler, M. Stemp, M. Barril, Third body effects material fluxes in tribocorrosion systems involving a sliding contact, Wear 256 (2004) 517524.

[10] Y. Yan, A. Neville, D. Dowson, S. Williams, Tribocorrosion in implants-assessing high carbon and low carbon Co-Cr-Mo alloys by in situ electrochemical measurements, Tribol. Int. 39 (2006) 1509-1517.

[11] M. Stemp, S. Mischler, D. Landolt, The effect of contact configuration on the tribocorrosion of stainless steel in reciprocating sliding under potentiostatic control, Corros. Sci. 45 (2003) 625-640.

[12] T.M. Manhabosco, I.L. Muller, Tribocorrosion of diamond-like carbon deposited on Ti6Al4V, Tribol. Lett. 33 (2009) 193-197.

[13] M. Rahman, I. Reid, P. Duggan, D.P. Dowlling, G. Hughes, M.S.J. Hashmi, Structural and tribological properties of the plasma nitrided Ti-alloy biomaterials: influence of treatment temperature, Surf. Coat. Technol. 201 (2007) 4865-4872.

[14] N. Heide, J.W. Schultze, Corrosion stability of TiN prepared by ion implantation and PVD, Nucl. Instrum. Meth. Phys. Res. B 80-81 (1993) 467-471.

[15] V.A Alves, R. Reis, IC. B. Santos, D.G. Souza, F Gonçalves, T.P Silva, A. Rossi, L.A. Silva, In situ impedance spectroscopy study of the electrochemical corrosion of $\mathrm{Ti}$ and Ti-6Al-4V in simulated body fluid at $25^{\circ} \mathrm{C}$ and $37^{\circ} \mathrm{C}$, Corros. Sci. 51 (2009) 2473-2482.

[16] M. Songür, H. Celikkan, F. Gömese, A.A. Sinkel, N.S. Altun, M.L. Aksu, Electrochemical corrosion properties of metal alloys used in orthopaedic implants, J. Appl. Electrochem. 39 (2009) 1259-1265.

[17] S. Rossi, L. Fedrizzi, T. Bacci, G. Pradelli, Corrosion behaviour of glow discharge nitrided titanium alloys, Corros. Sci. 45 (2003) 511-529.

[18] G.W. Walter, A review of impedance plot methods used for corrosion performance analysis of painted metals, Corros. Sci. 26 (1986) 681-703.

[19] M.F. Montemor, M.G.S. Ferreira, Electrochemical study of modified bis[triethoxysilylpropyl] tetrasulfide silane films applied on the AZ31 Mg alloy, Electrochim. Acta 52 (2007) 7486-7495.

[20] K. Holmberg, A. Matthews, Tribology series - Coatings Tribology Properties, Techniques and Applications in Surface Engineering, 28 ed., Elsevier, Amsterdam, 1994.

[21] M. Rahmann, I. Reid, P. Duggan, D.P. Dowling, G. Hughes, M.S.J. Hashmi, Structural and tribological properties of the plasma nitrided Ti-alloy biomaterials: Influence of the treatment temperature, Surf. Coat. Technol. 201 (2007) 4865-4872.

[22] F. Contu, B. Elsener, H.A. Böhni, Study of the potential achieved during mechanical abrasion and the repassivation rate of titanium and Ti6Al4V in inorganic buffer solutions and bovine serum, Electrochim. Acta 50 (2004) 3341.

[23] T.M. Manhabosco, I.L. Muller, Tribocorrosão da liga Ti6Al4V em solução salina tamponada com fosfato, Quím. Nova 32 (2009) 2263-2267.

[24] A. Neville, B.A.B. McDougall, Erosion- and cavitation-corrosion of titanium and its alloys, Wear 250 (2001) 726-735.

[25] A. Essner, K. Sutton, A. Wang, Hip simulator wear comparison of metal-onmetal ceramic-on-ceramic and crosslinked UHMWPE bearings, Wear 259 (2005) 992-995.

[26] A. Essner, G. Schmidig, A. Wang, The clinical relevance of hip joint simulator testing: In vitro and in vivo comparisons, Wear 259 (2005) 882-886.

[27] M.Z. Huq, J.P. Celis, Reproducibility of friction and wear results in ball-on-disc unidirectional sliding tests of TiN-alumina pairings, Wear 212 (1997) 151159. 